\title{
PREVALENCE AND RISK FACTORS ASSOCIATED WITH WORM INFESTATION IN PRE-SCHOOL CHILDREN (6-23 MONTHS) IN SELECTED BLOCKS OF UTTAR PRADESH AND JHARKHAND, INDIA
}

\author{
S. AWASTHI, T. VERMA, P. V. KOTECHA ${ }^{2}$, V. VENKATESH ${ }^{1}$, V. JOSHI', S. ROY ${ }^{2}$
}

\section{ABSTRACT}

BACKGROUND: Intestinal w orm infestation is widely prevalent in developing countries and can result in impaired nutrition and development. AIMS: To estimate prevalence of and risk factors for intestinal geohelminths and other intestinal parasites in children aged 6 to 23 months. SETTINGS AND DESIGN: Cross sectional study in rural India. MATERIALS AND METHODS: Proportionate population size sampling method was used to randomly select 15 villages per block. Thereafter, house-to-house survey was done to recruit eligible children and obtain fecal sample for microbiological examination. STATISTICAL ANALYSIS: Univariate distribution of variables was assessed and comparison between categorical variables and continuous variables was done using a Chi-square test and student's t-test, respectively. 0 dds ratio was calculated to assess associations. RESULTS: O verall 926 children were recruited and 909 fecal samples examined. Combined prevalence of infestation with intestinal geohelminths treatable by albendazole and other intestinal parasites non-treatable by albendazole was $50.3 \%$ (457/909) and 51.6\% (469/909), respectively. Exclusive use of hand pump water $(\mathrm{O} R=1.79, \mathrm{Cl}=1.36-2.35, \mathrm{P}<0.001)$ and use of hand pump water plus field defecation increased risk of geohelminthic infection $(O R=1.75 \mathrm{Cl}=1.34-2.30$, $P<0.001)$ while use of well water $(O R=0.45 \mathrm{Cl}=0.33-0.60, P<0.001)$ and exclusive use of soap and water practice for hand washing after defecation was protective (OR $=0.54, \mathrm{Cl}=0.40-0.73, \mathrm{P}<0.001)$. CONCLUSION: Since almost half the children are infected with intestinal geohelminths treatable by albendazole, targeted dew orming of population in this age group should be considered.

Key words: Hand pump, infant and pre-school children, risk-factors, rural India, worm infection, worm prevalence

Departments of Pediatrics and ${ }^{1}$ Pathology, CSMMU (Upgraded King George Medical College), Lucknow, ${ }^{2} \mathrm{~A} 2 Z$, The USAID Micronutrient and Child Blindness Project, Academy for Educational Development (AED), India

\section{Correspondence:}

Prof. Shally Awasthi,

C-29 Sector C, Chetan Vihar, Aliganj,

Lucknow (UP)-226 024, India

E-mail: sawasthi@sancharnet.in

DOI: 10.4103/0019-5359.48552

\section{INTRODUCTION}

The World Health Organization (WHO) estimates that infection with round worm (Ascaris lumbricoides), whipworm (Trichuris trichiura) and hookworms (Ancylostoma duodenale and Necator americanus) with associated morbidity, affect approximately 
250 million, 46 million and 151 million people, respectively. ${ }^{[1]}$ About half the population in South India ${ }^{[2]}$ and $50 \%$ of school children in tribal areas of Central India ${ }^{[3]}$ are infected with Ascaris lumbricoides, Trichuris trichiura and/ or hookworm. In the western part of Nepal, $86.7 \%$ of the pre-school children are infected with a single geohelminth infection and $13.3 \%$ with mixed infections. ${ }^{[4]}$ Thus, worm infestation as a public health problem needs immediate attention from policy makers in India and other South Asian countries. ${ }^{[5]}$

Young children have a high infection rate and suffer with a heavy worm burden of A. lumbricoides, Trichuris trichiura and/or schistosomes. ${ }^{[6]}$ These parasitic infections manifest themselves as reduced growth rates through impaired nutrient utilization. Consequently the children are not able to achieve their full potential in physical performance and education. ${ }^{[7,8]}$ Heavy hookworm burden is the major etiology for iron deficiency anemia in young children. ${ }^{[9-11]}$

The present study was conducted with the objective to assess the prevalence rates of intestinal geohelminth and other intestinal parasitic infections in 926 children of age group 6 to 23 months in rural setting of India. We also assessed the association of intestinal geohelminths with certain risk factors such as access to safe drinking water and hygiene related practices of the community.

\section{MATERIALS AND METHODS}

This cross sectional study was conducted in two blocks, one each from Uttar Pradesh and Jharkhand states. Gyanpur, which is one of the seven administrative blocks of Sant Ravidas Nagar District, was selected from Uttar Pradesh. Murhu, which is one of six administrative blocks of recently formed Khunti district, was chosen from Jharkhand.

The study was designed to include 375 children per block, assuming the prevalence of geohelminths to be $30 \%$, with a precision of $5 \%$, alpha-error of 0.05 and with the design effect of 2. Expecting a non-response rate of $20 \%$, final sample size was derived to be 450 for each block. A two-stage sampling strategy was deployed to select villages and to recruit children of age group 6-23 months. In first stage, villages were selected by proportionate population size sampling. From a fixed geographical location, all the villages within the two blocks were listed serially, along with their total population. After complete listing, the cumulative population for each village was calculated. Thereafter, the total block population was divided by 15 (since 15 was the number of villages to be sampled per block). Assuming that result of division to be ' $X$ ', which was a positive whole number $>0$, an EPI Info program was used to generate one random number between 1 and $X$. This was random value ' $R$ '. The village whose cumulative population contained this random number was selected as the first village to be sampled. There after ' $X$ ' was added to $R$ and the result gave the cumulative population, which was to be in the $2^{\text {nd }}$ village to be selected. This was continued till 15 villages from each block were selected. In the second stage, from each village 30 children were aimed to be included to reach the target sample of 450 .

After the identification of villages, a house- 
to-house survey was conducted within each village. The first child in the eligible age group was selected from a specific geographic direction in each village, and the rest of them were selected from the contiguous households till the required number of children was attained. Only one child per household was included after obtaining written informed consent from the parent/caregiver. This was continued till 30 children per village were recruited and a total of 926 children (6-23 months) were reached from 30 villages of each block.

A team of three trained staff members collected data on a pre-tested structured questionnaire. It was used to elicit information on the respondent's socio-demographic characteristics like religion, caste, quality of housing construction, sources of drinking water and presence of toilets in the house of the respondents. The literacy status of the respondents was classified as: uneducated, who could neither read nor write, literate who had the ability to read and write but without any formal education and educated who had formal schooling. Information on sanitation and hygiene related behavior like washing of hands after defecation was also obtained. The primary respondent for reporting was the mother of the child, the father acted as the next respondent. In case of absence of both of them, an adult in the household who remained with the child for most of the time was interviewed.

Fecal samples were collected in prepared, pre-weighed bottles containing formaline. The study team instructed parents/caregivers on the method of collecting pea size (approximately $10 \mathrm{gm}$ ) fecal samples. These were transported to the Chhatrapati Shahuji Maharaj Medical University, Lucknow for microbiological examination. A trained technician examined all the samples. Formol-Ether concentration method was used to increase the yield of helminth eggs ${ }^{[12]}$ using the guidelines provided by the World Health Organization. ${ }^{[13]}$ Seven species of intestinal helminthes or parasites were identified and categorized into either Group A - that were potentially treatable by a single dose (400 $\mathrm{mg}$ ) albendazole or in Group B- that were non-treatable by a single dose (400 $\mathrm{mg}$ ) albendazole. Group A included intestinal geohelminthic infections namely Ascaris lumbricoides, Hookworm and Trichuris trichiura while Group B included other intestinal parasites namely S. stercolis, Taenia, Entamoeba and Giardia. Validation measures ensured quality in data collection and fecal examinations. The village heads ('pradhans') were contacted within 48 hours to verify the process of data collection. Also, 10\% villages were re-visited by the principal investigator and $10 \%$ of fecal samples were re-examined by the microbiology investigator.

Statistical analysis was performed using SPSS software for Windows (version 10.0.1, SPSS UK Ltd, Chertsey, United Kingdom). Data was entered on Microsoft Access. Univariate distribution of all variables was assessed and comparison between categorical variables and continuous variables was done using a chisquare test and student's t-test, respectively. If one or two of the cells had numbers less than 5, Fisher's Exact Test was used. A ' $P$ ' value less than 0.05 was considered statistically significant, using a two-tailed distribution. To assess association of infestation of any intestinal geohelminth with various categorical 
variables, crude odds ratios with $95 \% \mathrm{Cl}$ were calculated and reported with a ' $P$ ' value.

\section{Ethical considerations}

The study was approved by the institutional ethics committee and written informed consent was taken from the parents or caregivers of the child.

\section{RESULTS}

Nine hundred and twenty-six children residing in 30 villages in each of two blocks totaling to 60 villages, were studied from July to September 2007 to estimate the prevalence of any intestinal geohelminthic infection or other intestinal parasitic infection and its risk factors. Fifty point nine percent $(n=472)$ recruited children were from Gyanpur and 49.1\% ( $\mathrm{n}=$ 454) were from the Murhu block. Combined mean ( $\pm S D$ ) age (in months) of the recruited 926 children was 14.56 ( \pm SD 5.611). Female to male ratio was 1:0.96.

Quantitative information on socio-economic status and behavioral practices was provided either by mother $(72.6 \%, \mathrm{n}=673)$ or by relatives/guardians $(18.0 \%, \mathrm{n}=167)$ or by the father $(9.3 \%, n=86)$ of the child. The respondents residing in these two blocks were comparable in terms of religion and caste. A majority of the respondents in Gyanpur (97.5\%, $n=460)$ and Murhu (88.6\%, $n=402)$ blocks were Hindu by religion. In addition, $92.8 \%$ ( $\mathrm{n}$ $=860$ ) of them were from the reserved caste. The proportion of the population belonging to Reserved Caste of Scheduled Caste or Scheduled Tribe in Gyanpur and Murhu block was $31.6 \%$, $(n=149)$ and $88.8 \%,(n=403)$ respectively while the proportion belonging to
Other Backward Class (OBC) in Gyanpur and Murhu blocks was $57.8 \%,(n=273)$ and $7.7 \%$, $(\mathrm{n}=35)$ respectively.

Certain socio-demographic characteristics of the study population and their hygiene related practices are shown in Table 1. A significantly high proportion of respondents in Gyanpur $(87.1 \%, n=411)$ and Murhu block $(68.2 \%, n$ = 331) commuted in non-motorized vehicles. In both the blocks only $5 \%$ sampled children were delivered institutionally with no significant difference $(P=0.304)$ in place of delivery between both blocks.

A majority (96.1\%, $\mathrm{n}=909)$ of parents/ caregivers provided fecal samples for examination of their child. The prevalence of geohelminth infection is tabulated [Table 2]. Combined prevalence of single and mixed geohelminthic infection treatable by albendazole was $50.3 \%$ (457/909) while

Table 1: Socio-demographic attainments and hygiene related practices of the respondents $(n=926)$

\begin{tabular}{lcc} 
& Gyanpur Block & Murhu Block \\
\hline Education Status of the Father & & \\
Uneducated & $107(22.7)$ & $294(64.8)$ \\
Literate & $349(73.9)$ & $152(33.5)$ \\
Educated & $16(3.4)$ & $8(1.8)$ \\
Types of House & & \\
Non Concrete ('Kutcha') & $260(55.1)$ & $427(94.1)$ \\
Concrete ('Pucca') & $151(31.9)$ & $10(02.2)$ \\
Semi-concrete (Both) & $61(12.9)$ & $17(03.7)$ \\
Sources of drinking water* & & \\
Tap & $24(5.1)$ & $2(0.4)$ \\
Hand Pump & $419(88.8)$ & $146(32.2)$ \\
Well & $90(19.1)$ & $311(68.5)$ \\
River & $1(0.2)$ & $19(4.2)$ \\
Child defecates * & & \\
Field & $459(96.8)$ & $441(96.9)$ \\
Sanitary latrine & $15(3.2)$ & $9(2.0)$ \\
At Home (make shift) & $0(0.0)$ & $5(1.1)$ \\
Wash hand after defecation * & & \\
Soap and Water & $81(17.2)$ & $258(56.8)$ \\
Water only & $6(1.3)$ & $4(0.9)$ \\
Ash/ Water & $8(1.7)$ & $63(13.9)$ \\
Mud/ Water & $422(89.4)$ & $163(35.9)$ \\
\hline
\end{tabular}

*Multiple replies 
Table 2: Prevalence of geohelminths and other intestinal parasites $(n=909)$

\begin{tabular}{lcccc}
\hline Geohelminths and other intestinal parasites & Combined & Gyanpur & Murhu & $P$ value \\
\hline A) & $(B)$ & $(C)$ & $(B$ vs. C) \\
Sample Size & 909 & 455 & 454 \\
Group A: Geohelminths treatable by albendazole & $\mathrm{n}(\%)$ & $\mathrm{n}(\%)$ & $\mathrm{n}(\%)$ \\
Single Infection & & & & \\
$\quad$ Ascaris lumbricoides & $292(32.1)$ & $191(41.9)$ & $101(22.3)$ & $<0.001$ \\
$\quad$ Hookworm & $35(3.9)$ & $28(6.1)$ & $07(1.5)$ & $<0.001$ \\
$\quad$ Trichuris trichiura & $24(2.6)$ & $12(2.6)$ & $12(2.6)$ & 0.996 \\
$\quad$ Prevalence single infection & $351(38.6)$ & $231(50.8)$ & $120(26.4)$ & $<0.001$ \\
$\quad$ Prevalence mixed infection & $106(11.7)$ & $69(15.2)$ & $37(8.1)$ & $<0.001$ \\
$\quad$ Combined prevalence of single and mixed & & & & \\
$\quad$ infection (Group A) & $457(50.3)$ & $300(65.9)$ & $157(34.6)$ & $<0.001$ \\
Group B: Other intestinal parasites non-treatable by albendazole & & & & \\
$\quad$ S.stercolis & $110(12.1)$ & $44(9.7)$ & $66(14.5)$ & 0.025 \\
$\quad$ Taenia & $170(18.7)$ & $79(17.4)$ & $91(20.0)$ & 0.300 \\
$\quad$ Entamoeba & $159(17.5)$ & $57(12.5)$ & $102(22.5)$ & $<0.001$ \\
$\quad$ Giardia & $30(3.3)$ & $15(3.3)$ & $15(3.3)$ & 0.995 \\
$\quad$ Overall prevalence Group B & $469(51.6)$ & $195(42.9)$ & $274(60.3)$ & $<0.001$ \\
\hline
\end{tabular}

prevalence of other intestinal parasites nontreatable by albendazole was 51.6\% (469/909). Ascaris lumbricoides was the leading cause of geohelminthic infection in both blocks. Prevalence of intestinal geohelminth infection (Group A) was more in Gyanpur block (65.9\%, $300 / 455)$ than in Murhu block (34.5\%, 157/454) $(P<0.001)$. Other intestinal parasites (Group B) were more prevalent in 60.3\% (274/454) in Murhu as compared to $42.9 \%(195 / 455)$ in Gyanpur block $(P=0.000)$.

Risk factors associated with any geohelminthic infections are given in Table 3 . While the exclusive use of soap and water after defecation and well water were protective for any geohelminth infection, exclusive use of handpump water and use of handpump water and the practice of field defection combined, placed the children at an increased risk of geohelminthic infection.

\section{DISCUSSION}

Our study, conducted to assess the prevalence rates and risk factors of intestinal geohelminths and other intestinal parasitic infections, has found that almost half of the young children suffer from intestinal geohelminth infections that are potentially treatable by a single dose of albendazole. Also we found that use of handpump water and open-air defecation placed the children with an increased risk of intestinal geohelminth infections.

In our study, $50.3 \%$ children were infected with single or mixed geohelminth infections (Group A) while $51.6 \%$ suffered from other intestinal parasites (Group B). Studies from Nigeria and Pakistan have reported prevalence rates of $44 \%$ and $77 \%$ respectively among young children $^{[14,15]}$ although an Ethiopian study found a much lower prevalence. ${ }^{[16]} A$ relatively high prevalence of intestinal geohelminth infections in these developing countries is due to poor socio economic conditions like presence of inadequate housing, low levels of education and awareness, poor health services, inadequate sanitation, lack of access to sanitation facilities and clean drinking water. ${ }^{[17]}$ Despite the presence of poor socio-economic conditions in Murhu block the prevalence of 
infection is less than that of Gyanpur block. This may be due to greater use of soap and water after defecation and drinking well water, both of which have been found to be protective against geohelminthic infections [Table 3].

Many researchers have established that age, socio-economic and behavioral factors play a definitive role in causing intestinal geohelminth infection. Characteristics like household crowding, level of education, religion, use of footwear when outdoors, defecation practices, cattle ownership and water sources have implications in spreading infection. ${ }^{[18]}$ In our study the exclusive use of soap and water practice after defecation was also protective for any geohelminthic infection $(\mathrm{OR}=0.54, \mathrm{Cl}=$ 0.40-0.73, $P<0.001$ ). A Keynesian study also found that households without soap had a 2.6 times higher risk of being infected with Ascaris lumbricoides compared with households where soap was available. ${ }^{[19]}$ Since a majority of the respondents in Gyanpur $(97.3 \%, \mathrm{n}=$ 472) and Murhu blocks $(97.1 \%, n=454)$ in our study defecated in the open air, we could not estimate any association between field defecation and positivity of infection in either blocks.

Sources of drinking water were also analyzed in this study and strong correlates were found between intake of hand pump water
(OR $=1.79,95 \% \mathrm{Cl}=1.36-2.35, P<0.001)$ and occurrence of infection. Others have found associations of infection with intake of ring-well water ${ }^{[19]}$ and river water ${ }^{[14]}$ which is inconsistent with what we found in our study. Probably, the hand pumps which are dug at the shallow level come in contact with raw sewage due to proximity with open drain/ canal, overflowing drains, physical contact with wastewater or with open defecation and public washing and thus provided optimum conditions for the survival and development of the eggs of Ascaris lumbricoides. Risk of untreated wastewater discharge in spreading of geohelminths especially Ascaris lumbricoides has also been reported by others. ${ }^{[19]}$

Preventive measures for safety of available drinking water and spreading awareness related to sanitation related behavior should be adopted to minimize the prevalence of worm infestation. Simple community based measures such as increasing public awareness about the drawbacks of open-air defecation, safe disposal of waste water and safe handling of drinking water can be used for easy and short-term results. Also, sanitation education campaigns are necessary to increase awareness of populations at risk to the relationship between deploying safe sanitation practices, sanitary conditions in general and helminthiasis.

Table 3: Risk factors associated with intestinal geohelminth infections (Group A) among preschool children in both blocks

\begin{tabular}{|c|c|c|c|c|}
\hline \multirow[t]{3}{*}{ Risk Factor } & \multicolumn{2}{|c|}{ Geohelminth Infections (Group A) } & \multirow[t]{3}{*}{ Odds Ratio $(95 \% \mathrm{Cl})$} & \multirow[t]{3}{*}{$P$ value } \\
\hline & Positive & Negative & & \\
\hline & $n(\%)$ & $n(\%)$ & & \\
\hline Exclusive use of soap and water & $119(26.0)$ & $178(39.4)$ & $0.54(0.40-0.73)$ & $<0.001$ \\
\hline Field defecation & $445(97.4)$ & $438(96.9)$ & $1.19(0.51-2.77)$ & 0.669 \\
\hline Well only & $117(25.6)$ & $197(43.6)$ & $0.45(0.33-0.60)$ & $<0.001$ \\
\hline Hand pump only & $272(59.5)$ & $204(45.1)$ & $1.79(1.36-2.35)$ & $<0.001$ \\
\hline Use of handpump and field defecation & $263(57.6)$ & $197(43.6)$ & $1.75(1.34-2.30)$ & $<0.001$ \\
\hline
\end{tabular}


Since the existent national policy on water and sanitation encourages the community to use water supplied from a tap or a hand pump/tube well situated within or outside the premises ${ }^{[20]}$ for health safety; measures need to be taken to maintain stringent standards in the installation of hand pumps. The hand pumps should be dug deeper and far away from the sewage tank to prevent their shallow depth from transmitting pathogenic contamination. ${ }^{[21]}$ Also, earlier studies on controlling helminth infections have suggested that single dose albendazole is a simple, sustainable and cost effective strategy if delivered through the nationwide Integrated Child Development Services (ICDS) program. [22] Such community based programs need to be strengthened.

The limitations of the study must be kept in mind. The study is cross-sectional in design and there might be potential information biases relating to the collection of questionnaire data. Information on the mother's literacy status, which might have been an important risk factor, was not collected. However, since we found a large proportion of fathers were without any formal schooling, we have a reason to assume that the proportion of literate mothers might have been even lower. Besides, the quantitative nature of data was a limitation in qualitatively exploring the reasons behind poor sanitation and related behavioral practices. Still, our sample size was large, standardized protocols were employed, and stool examination data was measured objectively.

In conclusion, almost half the preschool children in rural India have a high prevalence of intestinal geohelminths. Since these intestinal geohelminths are potentially treatable by a single dose albendazole, targeted deworming of population in this age group should be considered.

\section{ACKNOWLEDGMENTS}

We thank the Department of Health and Family Welfare, Government of Uttar Pradesh and Government of Jharkhand for permission and facilitation in conducting this study. Our special thanks to Mr. Manish Tripathi who managed and analyzed the data during the course of this study.

\section{REFERENCES}

1. Montresor A, Crompton DWT, Hall A, Bundy DA, Savioli L. Guidelines for the evaluation of soiltransmitted helminthiasis and schistosomiasis at a community level. World Health Organization, Geneva: 1998. WHO/CTD/SIP/ 98.1.

2. Mani TR, Rajendran R, Munirathinam A, Sunish IP, Md Abdullah S. Efficacy of co-administration of albendazole and diethylcarbamazine against geohelminthiases: A study from South India. Trop Med Int Health 2002;6: 541-8.

3. Chakma T. Prevalence of anaemia and worm infestation in tribal areas of Madhya Pradesh. $J$ Indian Med Assoc 2000;98:567-71.

4. Mukhopadhyay C, Wilson AG, Chawla K, Binu VS, Shivananda PG. Six year Geohelminth infection profile of children at high altitude in Western Nepal. BMC Public Health 2008;8:98. Available from: http://www.biomedcentral.com/14712458/8/98.

5. Chan MS, Medley G, Jamison D, Bundy DA. The evaluation of potential global morbidity attributable to intestinal nematode infections. Parasitology 1994;109:373-87.

6. Albonico M, Allen H, Chitsulo L, Engels D, Gabrielli AF, Savioli L. Controlling soil-transmitted 
helminthiasis in pre-school-age children through preventive chemotherapy. PLoS Negl Trop Dis 2008;2:e126.

7. Awasthi S, Bundy DAP, Savioli L. Helminthic Infections. BMJ 2003;19:885-8.

8. Kvalsvig JD, Cooppan RM, Connolly KJ. The effects of parasite infections on cognitive processes in children. Ann Trop Med Parasitol 1991;85:551-68.

9. Roche M, Layrisse M. Hookworm anaemia. Am J Trop Med Hyg 1966;15:1029-102.

10. Guyatt H. Do intestinal nematodes affect productivity in adulthood? Parasitol Today 2000;16:153-8.

11. Crompton DW, Nesheim MC. Nutritional impact of intestinal helminthiasis during the human life cycle. Ann Rev Nutr 2002;22:35-59.

12. Gillespie SH. Intestinal Nematodes. In: Gillespie $\mathrm{SH}$, Pearson RD, editor. Principles and practice of clinical parasitology. Vol. 21. New York: John Willy and Sons, Ltd; 2001. p. 562-83.

13. World Health Organization. Basic laboratory methods in medical parasitology. Geneva: The Organization; 1991.

14. Oyewole F, Ariyo F, Oyibo WA, Sanyaolu, Faweya $\mathrm{T}$, Monye $\mathrm{P}$, et al. Helminthic reduction with albendazole among school children in riverine communities of Nigeria. J Rural Trop Public Health 2007;6:6-10.

15. Hafeez R, Tahir Z, Chughtai AS. Incidence and intensity of soil transmitted helminths in a rural area of Lahore. Int J Pathol 2003;1:36-8.

16. Tadesse $G$. The prevalence of intestinal helminthes infections and associated risk factors among school children in Babile town, eastern
Ethiopia. Ethiop J Health Dev 2005;19:140-7.

17. De Silva NR, Jayapani VP, De Silva HJ. Socioeconomic and behavioral factor affecting the prevalence of geohelminths in preschool children. Southeast Asian J Trop Med Public Health 1996;27:36-42.

18. Traub RJ, Robertson ID, Irwin P, Mencke N, Thompson $\mathrm{RC}$. The prevalence, intensities and risk factors associated with geohelminth infection in tea-growing communities of Assam, India. Trop Med Inter Health 2004;9:688-701.

19. Stephenson LS, Latham MC, Adams EJ, Kinoti SN. Weight Gain of Kenyan School Children Infected with Hookworm, Trichuris trichiura and Ascaris lumbricoides is improved following Onceor Twice-Yearly Treatment with Albendazole. J Nutr 1993;123:656-65.

20. Planning Commsion. National Human Developement Report.2001. Available from http:// planningcommission.Nic.In/Reports/Genrep/ Nhdrep/Nhdch3.Pdf. [last assessed on $2008 \mathrm{Dec}$ 20].

21. Moubarrad FZ, Assobhei O. Health risks of raw sewage with particular reference to Ascaris in the discharge zone of El Jadida (Morocco). Desalination 2007;215:120-6.

22. Awasthi S, Peto R, Pande VK, Fletcher $\mathrm{RH}$, Read S, Bundy DA. Effects of deworming on malnourished preschool children in India: An open-labelled, cluster-randomized trial. PLoS Negl Trop Dis 2008;2):e223.

Source of Support: The Academy for Educational Development (AED), New Delhi, Conflict of Interest: None declared. 